\title{
Workplace Violence in Healthcare: A Single-Center Study on Causes, Consequences and Prevention Strategies
}

\author{
A Violência no Local de Trabalho em Instituições \\ de Saúde: Um Estudo Monocêntrico sobre Causas, \\ Consequências e Estratégias de Prevenção
}

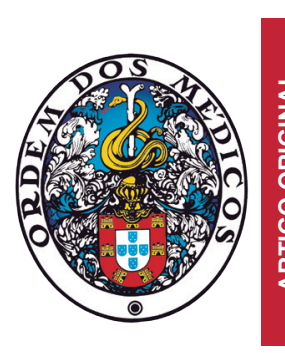

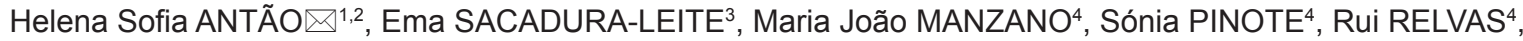 \\ Florentino SERRANHEIRA ${ }^{3}$, António SOUSA-UVA ${ }^{3}$ \\ Acta Med Port 2020 Jan;33(1):31-37 - https://doi.org/10.20344/amp.11465
}

\section{ABSTRACT}

Introduction: Workplace violence is one of the main risk factors in the professional world. Healthcare workers are at higher risk when compared to other sectors. Our study aimed to characterize physical and verbal violence in a public hospital and to define occupational health prevention and surveillance strategies.

Material and Methods: Single center observational cross-sectional study, carried amongst healthcare workers in a public hospital in Lisbon. A qualitative survey was carried out through six in-depth interviews. A quantitative survey was carried through questionnaires delivered to 32 workers. A significance level of $5 \%$ was accepted in the assessment of statistical differences. The Mann-Whitney test and the Fisher's exact test were used to calculate $p$ values.

Results: The main results are: (1) 41 violence incidents were reported in the quantitative phase; (2) $5 / 21$ [23.81\%] victims notified the incident to the occupational health department; (3) 18/21 [85.71\%] victims reported a permanent state of hypervigilance; (4) $22 / 28$ [78.57\%] participants self-reported poor or no familiarity with internal reporting procedures; (5) 24/28 [85.71\%] participants believed it is possible to minimize workplace violence.

Discussion: Workplace violence is favored by unrestricted access to working areas, absence of security guards and police officers or scarce intervention. The low notification rate contributes to organizational lack of action. The state of hypervigilance reported in our study reflects the negative effects of threatening occupational stressors on mental health.

Conclusion: Our results show that workplace violence is a relevant risk factor that significantly impacts workers' health in a noxious manner, deserving a tailored occupational health approach whose priority areas and strategies have been determined.

Keywords: Healthcare Workers; Occupational Hazard; Occupational Health; Prevention; Workplace Violence

\section{RESUMO}

Introdução: A violência no local de trabalho é um dos principais fatores de risco no mundo do trabalho. Os trabalhadores da saúde apresentam um risco superior. O nosso estudo teve como objetivo caracterizar a violência física e verbal num hospital público e definir estratégias de prevenção e vigilância em saúde ocupacional.

Material e Métodos: Estudo observacional transversal monocêntrico, conduzido num hospital público em Lisboa com trabalhadores da saúde. Foi realizado um inquérito qualitativo com entrevistas em profundidade a seis trabalhadores e um inquérito quantitativo com questionários a 32 trabalhadores. Aceitou-se um nível de significância de $5 \%$ na avaliação das diferenças estatísticas. 0 teste de Mann-Whitney e o teste exato de Fisher foram usados para calcular os valores de $p$.

Resultados: Os principais resultados são: (1) 41 episódios reportados na fase quantitativa; (2) 5/21 [23,81\%] vítimas notificaram o incidente; (3) 18/21 [85.71\%] vítimas reportaram estados de hipervigilância permanente; (4) 22/28 [78,57\%] participantes não conheciam ou conheciam mal os procedimentos de notificação; (5) 24/28 [85,71\%] consideravam possível minimizar o problema.

Discussão: A violência é favorecida pelo acesso livre às zonas de trabalho, ausência de agentes de segurança e polícia ou falta da respetiva intervenção. A baixa notificação contribui para a ausência de medidas organizacionais. O estado de hipervigilância relatado reflete o efeito prejudicial da exposição a fontes de stress e ameaça.

Conclusão: A violência no local de trabalho é um fator de risco relevante, com impacto negativo na saúde dos trabalhadores e merece uma abordagem individualizada no âmbito da saúde ocupacional, cujas áreas e estratégias prioritárias foram definidas neste estudo. Palavras-chave: Fatores de Risco Profissionais; Prevenção; Saúde Ocupacional; Trabalhadores da Saúde; Violência no Local de Trabalho

\section{INTRODUCTION}

Workplace violence is considered one of the most serious occupational hazards by the International Labour Office. ${ }^{1}$ The Occupational Safety and Health Administration (OSHA) defines workplace violence as any act or threat of physical violence, harassment, intimidation, or other threat-

ening disruptive behavior that occurs at the workplace, ranging from threats and verbal abuse to physical assaults and even homicide. ${ }^{2}$ Motivation to work, job security and job mobility have also been reported to be negatively impacted. ${ }^{3}$ The exposure to stressful events at work is likely to increase

1. Escola Nacional de Saúde Pública. Universidade NOVA de Lisboa. Lisboa. Portugal.

2. Emergency Department. Hospital Professor Doutor Fernando da Fonseca. Amadora. Portugal.

3. CISP - Centro de Investigação em Saúde Pública. CHRC - Comprehensive Health Research Center. Escola Nacional de Saúde Pública. Universidade NOVA de Lisboa. Lisboa. Portugal.

4. Occupational Health Department. Centro Hospitalar Universitário de Lisboa Central. Lisboa. Portugal.

$\square$ Autor correspondente: Helena Sofia Antão. sofintao@gmail.com

Recebido: 22 de outubro de 2018 - Aceite: 10 de julho de 2019 | Copyright @ Ordem dos Médicos 2020 
cognitive activation that can be described as worrying or having repetitive thoughts, triggering autonomic arousal and emotional stress. ${ }^{4}$ Length of exposure has been referred as determinant to the severity of these effects. ${ }^{4,5}$ The impact of workplace violence on health is of greater concern when workers are permanently involved with other citizens which is the case of healthcare ${ }^{3}$ where the risk of aggression is four times higher than in the general private sector. ${ }^{6}$ Additionally, it threatens the quality of the care provided to patients. ${ }^{1,7}$ According to the European Foundation for the Improvement of Living and Working Conditions (Eurofound) $14.9 \%$ of workers in the European Union suffer some kind of workplace violence. ${ }^{3}$

Notification is the key to identify and prevent this hazard. In the past, aggressions have been considered confidential by healthcare workers and their importance has been minimized by hospital administrations. ${ }^{8}$ Aggressions were felt as a part of their job and notifying was found useless. ${ }^{9}$ Some workers limit their notifications to verbal reports to supervisors. ${ }^{10}$ Some authors explain the rising trend of workplace violence in healthcare based on an increase in consumption of illicit drugs, ignorance, intolerance and lack of respect that became widespread in some societies. ${ }^{9,11}$

Hospitals are especially concerned about the rising incidence of violent events. ${ }^{12}$

Workplace violence prevention strategies can be included into two broad categories: pre-incident strategies, which encompass legislation and management (e.g. organizational policies, work design), design of the work environment, education and training; and post-incident strategies, which include incident reporting and psychological intervention for affected workers. ${ }^{13}$

Some of the actions proposed to control this hazard include administrative measures such as flagging the files of patients with a history of violence against healthcare workers, ${ }^{14}$ penalties to perpetrators of violent actions against medical workers ${ }^{8}$ and, on a broader scale, teaching the youngest members of the population to respect and assist medical personnel. ${ }^{8}$

Fleming and Harvey ${ }^{15}$ proposed a structural approach to the problem where risk assessment (including worksite audits, training assessments and past violence incident reviews) plays a major role. These authors also highlighted the need for an adequate number of healthcare workers (since long waiting times increase the odds of patient hostility) and safety personnel. Gatekeeping working areas should ensure minimal public access to rooms where patients receive medical care..$^{15}$

Hamblin et $\mathrm{al}^{7}$ described a systematic approach to violence prevention supported by a "Checklist of Suggested Prevention Strategies for Workplace Violence in Hospital Units".

Arnetz et al succeeded in demonstrating significant differences in the progression of violence indexes in a 2-year follow-up randomized control trial where workplace interventions were supported by checklists and implemented by interdisciplinary teams while performing their usual daily activities. ${ }^{16}$

Fully understanding the phenomenon of workplace violence and setting up an effective occupational health plan had been defined as one of the Occupational Health Department needs for the year of 2018 in a hospital located in Lisbon, Portugal. Our research was designed to meet these needs.

The present study therefore aimed to: (1) Characterize physical and verbal violence regarding the circumstances of the occurrence, impact and consequences on workers; (2) Assess the level of familiarity of workers with internal notifications procedures and the extent of their application;

(3) Collect suggestions from workers on how to avoid or minimize workplace violence incidents and (4) Define interventional strategies directed to the improvement of working environment safety.

\section{MATERIAL AND METHODS}

\section{Study design, population and procedures}

This was a single center observational cross-sectional study, carried in a public hospital located in Lisbon from April to May 2018.

To be enrolled, individuals had to have experienced or witnessed physical or verbal violence within the previous 24 months and belong to one of the following professional groups: medical doctors, nurses, nursing assistants and technical assistants.

An exploratory qualitative survey was carried out through semi-structured in-depth interviews with six workers selected by the occupational health psychologist from the violence incidents notification registry on a most recent entrance basis. The registry is drawn from notifications made by workers through an interface available at their working terminals, the Health Event \& Incident Management, HER+. Oral consent was obtained prior to the interview scheduling.

A quantitative survey was carried out in the emergency department based on a mixed open and closed-ended questionnaire delivered to workers who agreed to participate after being opportunistically selected at their workplace (workers circulating in the emergency room areas during the aforementioned period to carry the survey were approached and invited to participate).

The questionnaires were delivered to a sample of 32 workers. The authors considered this sample size an acceptable trade-off between the size of the population (272 workers) and the available human and time resources.

Both surveys were performed by one of the authors.

\section{Script and questionnaires}

The script and the questionnaires administered were specifically built for the present study.

The exploratory qualitative phase script was based on the available literature. ${ }^{11,17,18}$ It included three sections: section $A$ was directed to the experience of violence itself (description of the episode of violence, circumstances, consequences and actions), section B was directed to perceptions on workplace safety and section $C$ aimed to assess 
the interviewee insight on the importance and prevention of workplace violence.

The quantitative phase questionnaire was based on the hospital formulary for workplace violence analysis and on the qualitative phase outcomes. It included two sections: section $A$ was aimed at victims of violence and section $B$ was aimed at witnesses of violence incidents. Participants could fill in both sections. The two sections included both open-ended and closed-ended questions concerning: (1) type of violence (physical or verbal); (2) whether the aggressor was a patient, a patient next of kin or a co-worker; (3) circumstances of the occurrence; (4) incident description; (5) presumed motives for the aggression; (6) victim's reactions and attitudes; (7) level of satisfaction towards the way the institution coped with the incident; (8) personal impact suffered by the victim; (9) possibility and ways of avoiding workplace violence; (10) level of familiarity about internal procedures on workplace violence and (11) whether the strategies recommended in those procedures were implemented.

Given the observational character of the study, authors declared that this study did not require informed consent or review/approval by the appropriate ethics committee.

\section{Data analysis}

In the qualitative phase, handwritten notes were taken during the in-depth interviews. Each interview's content was summarized in sections covering the main qualitative outcomes: description of the incident, sequelae and consequences, attitudes, safety perceptions, organizational level of concern, problem dimension and suggestions. The goal of this simplified analysis was to highlight the victim's experience and to bring to life particular phenomena associated with these experiences. ${ }^{19}$

Upon completion and collection of the quantitative phase questionnaires, demographics and answers to closedended questions were recorded in spreadsheets. Answers to open-ended questions were coded and classified into categories. Answers were screened for consistency, namely, comparison between answers to questions common to sections $A$ and $B$, personal impact scorings and comparison between answers provided to level of familiarity about internal procedures and implementation of recommended strategies.

Statistical analyses were performed using Microsoft Excel 2016 MSO, Open Epi - Open Source Epidemiologic Statistics for Public Health 3.01 and Social Science Statistics 2019. Descriptive statistics were provided for all items. Inference statistics calculations were used to assess the differences between means and proportions and the association between categorical variables; the level of significance accepted was of $5 \%$. The Mann-Whitney test and the Fisher's exact test were used to calculate $p$ values.

\section{RESULTS \\ Demographics}

In the quantitative phase, 28 workers returned valid filled in questionnaires, which corresponds to $10.3 \%$ of the emergency department staff.

The demographic characteristics of the survey population are depicted in Tables 1 and 2.

\section{Qualitative phase}

In the qualitative phase, interviewees reported mostly incidents of physical violence where the aggressor was either a patient, a patient next of kin or a co-worker. Some incidents occurred in circumstances where the victim was in charge either of deciding the admission of a patient to a clinical meeting or of gatekeeping the patient next of kin's admission to the care providing area. There were also reports of incidents involving aggressions by an elderly disturbed patient whose psychiatric medication had been discontinued and a victim's subordinate in the context of shift work scheduling decisions. The interviewees mentioned unrestricted access to working areas, absence of safety agents and police officers (or lack of their active interventions) as

Table 1 - Demographic characteristics of the qualitative study participants $(n=6)$

\begin{tabular}{lcccc} 
Participants & Gender & $\begin{array}{c}\text { Age } \\
\text { (years) }\end{array}$ & $\begin{array}{c}\text { Professional } \\
\text { category/ department }\end{array}$ & $\begin{array}{c}\text { Tenure in the hospital } \\
\text { (years) }\end{array}$ \\
\hline Participant 1 & M & 52 & Technical assistant/ Emergency & 10 \\
Participant 2 & F & 59 & Nurse/ Urology & 37 \\
Participant 3 & F & 50 & Nurse/ Orthopedics & 28 \\
Participant 4 & F & 58 & Doctor/ Pediatric emergency & 18 \\
Participant 5 & F & 34 & Nurse/ Internal medicine & 11 \\
Participant 6 & F & 44 & Nurse assistant/ External consultation & 14 \\
\hline
\end{tabular}

Table 2 - Demographic characteristics of the quantitative study participants $(n=28)$

\begin{tabular}{|c|c|c|c|c|c|}
\hline Variable & Medical Doctors & Nurses & NA & TA & Total \\
\hline$n$ & 12 & 12 & 3 & 1 & 28 \\
\hline Gender (M/F) & $4 / 8$ & $4 / 8$ & $0 / 3$ & $0 / 1$ & $8 / 20$ \\
\hline Age (years) mean $\pm \mathrm{SD}$; median & $41.58 \pm 11.65 ; 38.50$ & $38.08 \pm 8.92 ; 42.00$ & $53.34 \pm 5.51 ; 56.00$ & $50 ; 50$ & $41.64 \pm 10.65 ; 42.00$ \\
\hline Tenure in the hospital (years) mean $\pm \mathrm{SD}$; median & $14.67 \pm 10.66 ; 13.50$ & $13.50 \pm 10.05 ; 16.50$ & $17.67 \pm 2.52 ; 18.00$ & $25 ; 25$ & $14.86 \pm 9.67 ; 16.50$ \\
\hline
\end{tabular}


favoring the incidents' occurrence. Most of the interviewees reported psychological sequelae; nevertheless, severity seems to dilute over time. Some expressed feelings of determination and assertiveness when figuring out how they would act if similar situations happened again. Hospital management is found not to be sufficiently concerned or aware of the problem and not having violence prevention as a top priority. Some of the interviewees believe notifying is useless.

\section{Quantitative Phase Types of violence}

In the quantitative phase of the study, 28 healthcare workers answered valid questionnaires $(10.8 \%$ of the emergency department staff). A total of 41 violence incidents were reported. The number of incidents per type of violence are summarized in Fig. 1. There were no significant gender differences in the victims' group: $36.36 \%$ (IC 95\% [16.26\% - $56.47 \%]$ ) of males in the victims' group versus $30.00 \%$ (IC 95\% [9.92\% - 50.08\%]) in the witnesses' group ( $p$ value $=0.4574)$. Violence witnesses reported more physical violence incidents than verbal incidents. Verbal violence was described as "insults", "threats", "obscene words and gestures", "violent speech" and "chiding" or simply designated as "verbal violence". Physical violence was described as "kicking", "tearing the doctor's clothes", "hand raising at the victim", "punch attempt" or simply "physical aggression".

\section{Motives}

According to the participants, the main reasons underlying the aggressions were "long waiting time", "patients and population rudeness/ disrespect towards healthcare professionals" and "psychiatric disturbance". Fig. 2 depicts the absolute number of incidents attributable to each of these classes.

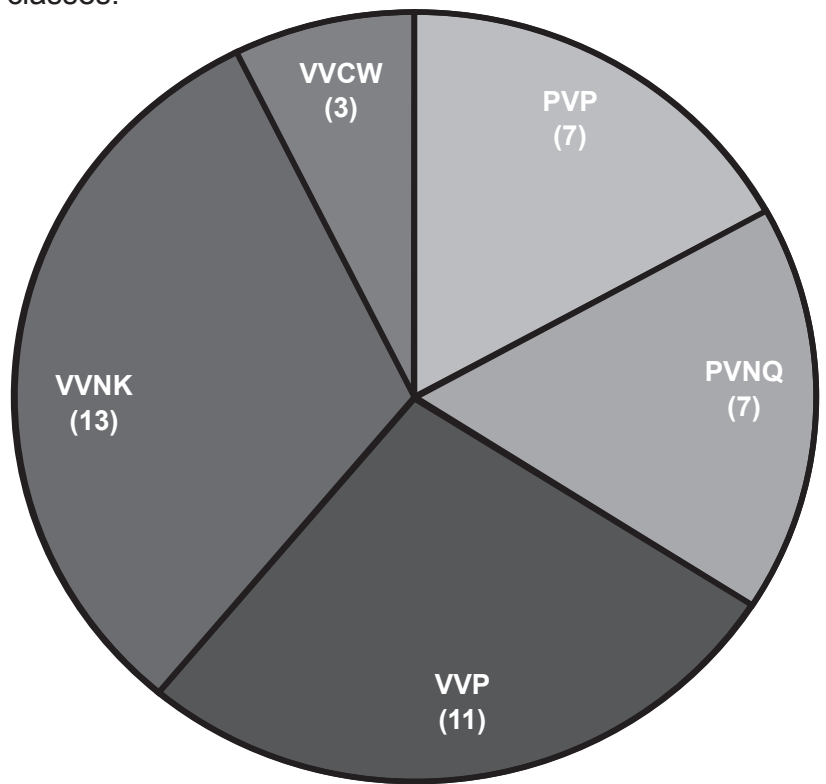

Figure 1 - Violence type, number of incidents $(n=41)$

PVP: physical violence from patient; PVNK: physical violence from next of kin; VVP verbal violence from patient; VVNK: verbal violence from next of kin; VVCW: verbal violence from co-worker

\section{Reactions and attitudes}

Only five out of the 21 participants who were victims of aggression $(23.81 \%)$ notified the incident, all of them in a context of verbal violence. The main attitudes taken were "asking the aggressor to stop" (14) and "calling the police" (7). None of the victims stopped working or went on sick leave because of the aggression.

\section{Satisfaction towards the institution}

Most participants answered the specific question on the level of satisfaction towards the way the institution coped with the incident by choosing the option "neither satisfied nor unsatisfied". Although physical violence victims showed lower satisfaction levels than verbal violence victims, the difference was not statistically significant (mean value 3.40 IC 95\% [2.92 - 3.88] vs 3.13 IC 95\% [2.72 - 3.54], $p$ value $=0.4295)$. The reasons pointed out for dissatisfaction were "absence of action", "no changes have been made", "absence of support to workers", "it is pointless to make a notification", "no consequences for the aggressor".

\section{Personal impact and consequences to the victim}

Sixteen out of the 21 victims $(76.19 \%)$ reported having experienced at least one of the five personal impacts listed: disturbing and recurrent memories or thoughts, avoiding thinking or talking about the incident, being hypervigilant, suffering from insomnia or loss of appetite and having to make an effort to work. Being hypervigilant was the most mentioned, chosen by 15 out of the 21 victims $(71.43 \%)$.

In the witnesses' group, 12 out of $18(66.67 \%)$ believed the violence incident changed the way the victim faced work, including job satisfaction and intent to leave, and pointed out feelings of fear, unsafety, sadness, demotivation, exhaustion, stress and lack of professional recognition.

Although a higher proportion of participants in the victims' group reported a negative personal impact compared to the witnesses' group on the same subject, the difference was not statistically significant (76\%; IC 95\% [55\% - 97\%] vs $55 \%$; IC95\% [33\% - 77\%], $p=0.1721)$.

The highest average score of agreement was found to the sentence "I am proud of my job" and lowest score was found to the sentence "I am thinking about quitting or asking to be moved to a different department (3.69 and 1.33,

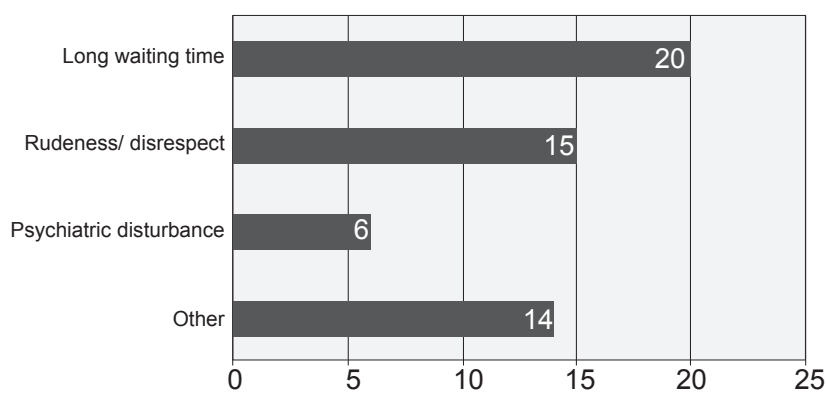

Figure 2 - Presumed aggressor's motives $(n=55)$

'Other' is a heterogeneous class that includes mentions to the aggressor's personality traits and emotions, lack of information provided to the patient/ next of kin and facilities unfriendly features. 
respectively, in a scale of 0 - 4, where 0 stood for "never" and 4 stood for "always"). Table 3 summarizes the answers provided to this question.

\section{Familiarity with internal procedures on workplace vio-} lence

Most participants (22 out of $28,78.57 \%$ ) self-reported poor or no familiarity with the hospital's internal reporting procedures on workplace violence. Those who had been working in the hospital for less than five years self-reported higher unfamiliarity when compared to those with a longer working history; the difference was statistically significant (mean value 3.75 ; IC 95\% [3.43 - 4.07] vs 2.89; IC 95\% $[2,45-3,34], p$ value $=0.0414$, in a scale of $1-4$, where 1 stood for "I am familiar with the procedures" and 4 stood for "I am not familiar with the procedures"). Fig. 3 shows the level of familiarity with internal procedures on workplace violence self-reported by all participants in the quantitative study sample.

\section{Implementation of recommended strategies}

Only eight out of the 21 victims (38.10\%) declared having implemented specific strategies recommended by the hospital's internal procedures for situations of workplace violence; these ranged from verbal communication with the aggressor ("dialogue", "explanations for the causes of delay", "speak calmly") to notification and request for help.

\section{Ways to avoid or minimize workplace violence}

Only four out of 28 (14.29\%) replied negatively to the answer "Do you believe it is possible to avoid or minimize workplace violence?". Suggestions on how it could be avoided or minimized were provided by 23 workers and ranged from gatekeeping of working areas, increasing the number of security guards and healthcare workers in the emergency department (for shorter waiting times), to information about waiting times and programs designed to increase the respect towards healthcare professionals. Fig. 4 depicts the number of answers per class of suggestions.

\section{DISCUSSION}

This study is probably one of the first to comprehensively describe workplace violence in a healthcare organization using concomitantly qualitative and quantitative surveys with the specific goal of designing a tailor-made Occupational Health prevention program.

It is known that the presence of security guards in healthcare institutions discourage aggressive behaviors and have been associated with improved feelings of safety in healthcare workers. ${ }^{20}$ The phenomenon of workers mistrusting the usefulness of the notification process has been previously reported. $6,18,21$ It has also been described that the productivity and commitment of workers increase when management teams show a candid interest in employees and in their behaviors (a phenomenon described as the 'Hawthorne effect'). ${ }^{6}$ This is especially relevant for healthcare workers due to the inner rhythm and intensity of their job profile. It is highly undesirable that this feeling of uselessness towards notification becomes generalized, since notification is the corner stone of understanding and

Table 3 - Personal impact of the violence incident $(n=21)$

\begin{tabular}{|c|c|c|c|}
\hline Personal impact - items & $\begin{array}{c}\text { Number of participants } \\
\text { scoring } \geq 1\end{array}$ & Mean score & Min - Max \\
\hline I have disturbing and recurrent memories or thoughts & 7 & 2.43 & $1-4$ \\
\hline I avoid thinking or talking about the episode & 8 & 2.38 & $1-4$ \\
\hline I am hypervigilant & 18 & 2.27 & $1-4$ \\
\hline I suffer from insomnia or loss of appetite & 1 & 2.00 & $2-2$ \\
\hline I have to make an effort tp go to work & 7 & 2.14 & $1-4$ \\
\hline I feel enough energy to do my job & 13 & 2.92 & $1-4$ \\
\hline I am proud of my job & 16 & 3.69 & $2-4$ \\
\hline I am thinking about quitting or asking to be moved to a different department & 6 & 1.33 & $1-4$ \\
\hline
\end{tabular}

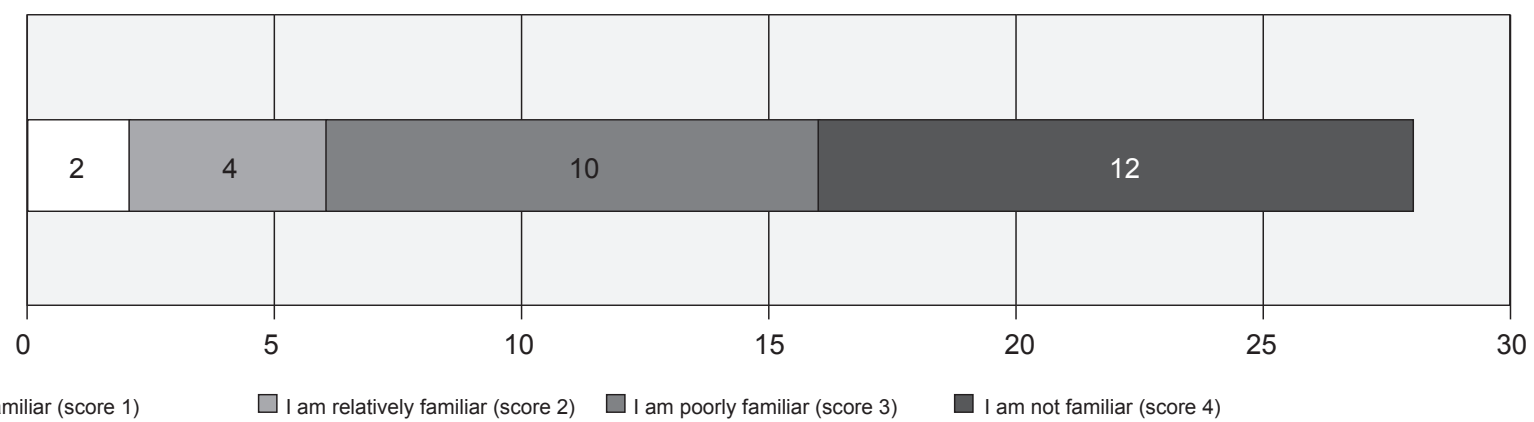

Figure 3 - Level of unfamiliarity with internal procedures on workplace violence $(n=28)$

[mean \pm SD: $3.14 \pm$ 0.93; median: 3; P25: 3; P75: 4] 


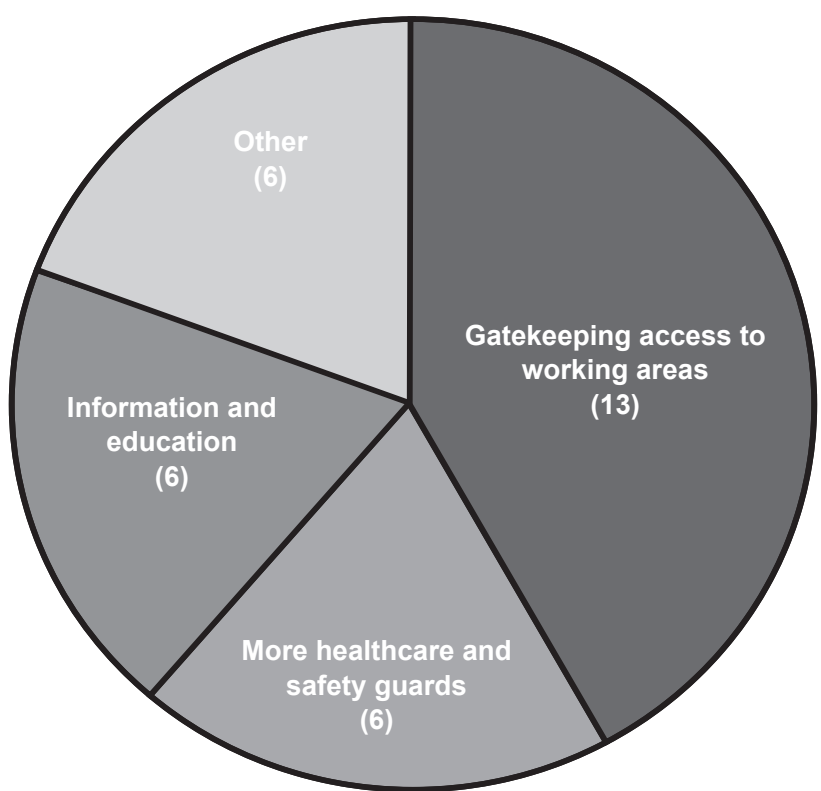

Figure 4 - Ways of avoiding or minimizing workplace violence $(n=31)$

effectively approaching the problem of workplace violence. Blando et $a^{/ 6}$ have underlined that an intense 'customer service' focus may worsen workplace violence by supporting a "the customer is always right" mindset which can lead to little or no action taken by intimidated healthcare professionals when faced with patients or their next of kin exhibiting abusive behaviors.

Because our quantitative phase was carried out in an emergency department, the 'healthy worker effect', through which workers who have experienced severe workplace violence episodes, resulting in serious sequelae, are less likely to keep on working in risky environments like emergency departments, ${ }^{20}$ may explain the self-reported low intention to quit and the high level of job pride.

Although our study had not been designed to determine frequencies of occurrence, a higher number of verbal violence incidents have been reported which is aligned with previous findings. ${ }^{21}$

Descriptions and motives mentioned for both verbal and physical violence are similar to those described elsewhere, although alcohol and drug abuse (classified as psychiatric disturbances in our study) seem to have a lower expression.

The low number of self-reported notifications (5 out of 21 victims, $23.81 \%$ ) is consistent with the qualitative phase findings and strongly adds to the vicious circle of ignorance and organizational lack of action that we have already referred to.

The state of hypervigilance self-reported by most of the victims (18 out of $21,85.71 \%$ ) reflects the prolonged cognitive and physiological activation related with repeated exposures to threatening stressors. ${ }^{22}$ The opinions expressed by witnesses about the personal impact and consequences on victims (two thirds of the participants describing these effects as fear, feelings of unsafety, sadness, demotivation, exhaustion, stress and lack of professional recognition as described in the results section) are also consistent with the theoretical background of workplace violence.

Some of the findings concerning the noxious effects of workplace violence have also been described in burnout studies in healthcare workers that have been previously carried out in our country, ${ }^{23}$ although our study reflects mainly feelings of emotional exhaustion rather than cynicism or reduced personal accomplishment.

One of our most concerning findings is the participants' unfamiliarity with internal procedures on workplace violence. This unfamiliarity, common in organizations as described by other authors, ${ }^{13,24}$ adds to and worsens the feelings of unsafety and loss of control experienced in conflict situations; the fact that it was found to be higher amongst workers with shorter tenures is of special concern, since it is expected that procedural details are provided to workers as soon as they join the organization.

The three types of suggestions provided by participants on how to avoid or minimize workplace violence (gatekeeping the access of patients/ next of kin to working areas, increasing the number of healthcare workers and security guards, informing and educating patients and the population) are adjusted to the deficiencies found in our study and it is our conviction that they should be taken into account when setting up an occupational health program specifically in this hospital.

Based on other studies ${ }^{14-18}$ and on our own knowledge of occupational health issues, we recommend that interventional strategies directed to the improvement of the safety of the working environment should also include a clear endorsement from top management, notification encouragement across the whole organization, risk assessment and stratification to prioritize interventions amongst the various physical areas, training and follow-up on workplace violence procedures provided to all workers at risk, definition of sanctions to violent patients and their next of kin and ensuring sufficient occupational health personnel so that all strategies can be successfully implemented. These prevention strategies should be complemented by a medical surveillance protocol specifically directed to workers at higher risk, including those who have been victims of violence incidents. This surveillance protocol should also specifically ensure the monitoring of workers' mental health.

The main limitations of our study are the small sample size, the opportunistic basis for selection of participants (instead of a randomization approach) and the absence of formal quality control in the qualitative phase. As additional limitations, we point out two aspects that may have contributed to an information bias of unknown extent. First, because it was based on questionnaires directed to events that could have happened up to 24 months before the time of enquiry, the accuracy of some of the data collected could have been impaired by memory. Second, having only listened to one version of the facts (aggressors have not been enquired) could have also led to a somehow distorted picture of the violence incident and its circumstances. 
Finally, the type of physical injury as well as its location, severity and prognosis were not explored in depth.

\section{CONCLUSION}

Our results show that workplace violence is an important occupational hazard that significantly impacts workers' health and wellbeing in a noxious manner. Familiarity with internal notification procedures and workplace safety are areas of improvement that have been clearly identified, as well as interventional strategies directed at these improvements. Specific programs designed to increase notification rates should also be further studied in order to identify best in class strategies.

\section{PROTECTION OF HUMANS AND ANIMALS}

The authors declare that the procedures were followed according to the regulations established by the Clinical Research and Ethics Committee and to the Helsinki
Declaration of the World Medical Association.

\section{DATA CONFIDENTIALITY}

The authors declare having followed the protocols in use in their working center regarding data publication. Individuals' participation demanded an oral consent. Written consents were waived.

\section{CONFLICTS OF INTEREST}

The authors have no conflicts of interest to declare.

\section{FUNDING SOURCES}

This research has not been funded.

\section{ACKNOWLEDGEMENTS}

The authors would like to thank Professor Baltazar Nunes, head of INSA's Epidemiological Research Unit, for his contribution to the statistical review of this manuscript.

\section{REFERENCES}

1. International Council of Nurses, Public Services International, World Health Organization, International Labour Office. Framework Guidelines for Addressing Workplace violence in the Health Sector: The training manual; 2005 [accessed on 2019 Jun 6]. Available at: https://www.ilo. org/safework/info/instr/WCMS_108542/lang--en/index.htm.

2. Occupational Safety and Health Administration. Workplace Violence [accessed on 2019 Jun 6]. Available at: https://www.osha.gov/SLTC/ workplaceviolence/.

3. Eurofound (2015), Violence and harassment in European workplaces: Causes, impacts and policies, Dublin [accessed on 2019 Jun 6]. Available at: https://www.eurofound.europa.eu/sites/default/files/ef_ comparative_analytical_report/field_ef_documents/ef1473en.pdf.

4. Reknes I, Notelaers G, Magerøy N, Pallesen S, Bjorvatn B, Moen BE, Einarsen S. Aggression from patients or next of kin and exposure to bullying behaviors: a conglomerate experience? Nurs Res Pract. 2017: 1-12.

5. Fang $H$, Zhao $X$, Yang $H$, Sun $P$, Li $Y$, Jiang $K$, Wu $Q$. Depressive symptoms and workplace-violence related risk factors among otorhinolaryngology nurses and physicians in Northern China:a crosssectional study. BMJ. 2018;8:1-9

6. Blando J, Ridenour M, Hartley D, Casteel C. Barriers to effective implementation of programs for the prevention of workplace violence in hospitals. Online J Issues Nurs. 2015;20.

7. Hamblin LE, Essenmacher L, Upfal MJ, Russell J, Luborsky M, Ager $\mathrm{J}$, Arnetz JE. Catalysts of worker-to-worker violence and incivility in hospitals. J Clin Nurs. 2015;24:2458-67

8. Hinsenkamp M. Int Orthop (SICOT) (2013) 37: 2321. [accessed on 2019 Jun 6]. Available at: https://doi.org/10.1007/s00264-013-2129-5.

9. Gallant-Roman MA. Strategies and tools to reduce workplace violence. AAOHN J. 2008;56:449-54.

10. Findorff MJ, McGovern PM, Wall MM, Gerberich SG. Reporting violence to a health care employer: a cross-sectional study. AAOHN J. 2005;53: 399-406.

11. Wolf LA, Dela AM, Perhats C. Nothing changes, nobody cares: Understanding the experience of emergency nurses physically or verbally assaulted while providing care. J Emerg Nurs. 2014;40:305-10.

12. Arnetz J, Lipscomb J, Ogaitis J. In search of effective solutions to curb workplace violence. ED Manag. 2017;29:41-4.

13. Wang S, O'Brien-Pallas LL, Hayes L. A review and evaluation of workplace violence prevention programs in the health sector. Toronto: Nursing Health Services Research Unit. 2008 [accessed on 2019 Jun 6]. Available at: https://pdfs.semanticscholar.org/7733/ f6e7d378ae23690372cde9b8c69484d275de.pdf.

14. Groenewold MR, Sarmiento RF, Vanoli K, Raudabaugh W, Nowlin S, Gomaa A. Workplace violence injury in 106 US hospitals participating in the Occupational Health Safety Network (OHSN), 2012-2015. Am J Ind Med. 2018;61:157-66.

15. Fleming $P$, Harvey HD. Strategy development in dealing with violence against employees in the workplace. Perspect Public Health. 2002;122: 226-32.

16. Arnetz JE, Hamblin L, Russell J, Upfal MJ, Luborsky M, Janisse J, Essenmacher L. Preventing patient-to-worker violence in hospitals: outcome of a randomized controlled intervention. J Occup Environ Med. 2017;59:1-23.

17. Copeland D, Henry M. Workplace violence and perceptions of safety among emergency department staff members: Experiences, expectations, tolerance, reporting, and recommendations. Int J Trauma Nurs. 2017;24: 65-77.

18. Ramacciati N, Ceccagnoli A, Addey B, Rasero L. Violence towards emergency nurses. The Italian National Survey 2016: a qualitative study. Int J Nurs Stud. 2018;81:21-9.

19. Streubert H, Carpenter D. Qualitative research in nursing, $5^{\text {th }}$ ed. Philadelphia: Wolter Kluwer Health, Lippincott Williams \& Wilkins. 2011.

20. Partridge B, Affleck J. Verbal abuse and physical assault in the emergency department: Rates of violence, perceptions of safety, and attitudes towards security. Australas Emerg Nurs J. 2017;20:139-45.

21. Nikathil S, Olaussen A, Gocentas RA, Symons E, Mitra B. Workplace violence in the emergency department: A systematic review and metaanalysis. Australas. 2017;29:265-75.

22. Ursin H, Eriksen HR. The cognitive activation theory of stress. Psychoneuroendocrinology, 2004; 29: 567-92.

23. Maroco J, Maroco AL, Leite E, Bastos C, Vazão MJ, Campos JADB Burnout em profissionais da saúde portugueses: Uma análise a nível nacional. Acta Med Port. 2016;29:24-30.

24. Findorff, MJ, McGovern PM, Sinclair S. Work-related violence policy: A process evaluation. AAOHN J. 2005;53:360-9. 